$9^{\text {th }}$ International Conference on Heat Transfer, Fluid Mechanics and Thermodynamics

16 - 18 July 2012

Malta

\title{
ANNULAR IMPINGING JET CONTROLLED BY RADIAL SYNTHETIC JETS
}

\author{
Trávníček Z. ${ }^{1}{ }^{*}$, Tesař V. ${ }^{1}$, Broučková Z. ${ }^{1,2}$ and Peszyński K. ${ }^{3}$ \\ *Author for correspondence \\ ${ }^{1}$ Institute of Thermomechanics AS CR, v.v.i., Dolejškova 5, Prague, Czech Republic \\ ${ }^{2}$ CTU Faculty of Mechanical Engineering, Technická 4, 16607 Prague 6, Czech Republic \\ ${ }^{3}$ University of Technology and Life Sciences, Bydgoszcz, Poland \\ E-mail: tr@it.cas.cz
}

\begin{abstract}
This experimental study focuses on generation and control of annular impinging jets. An annular nozzle was designed with an active flow control system using twelve radial synthetic jets issuing from the central body of the nozzle. Measurements of the wall pressure and wall mass transfer were performed with air as the working fluid. The control action causes modification of the flowfield resulting in changes of the corresponding heat/mass transfer distributions. The convective transfer rate on the stagnation circle can be demonstrably enhanced by $20 \%$ at a moderate nozzle-to-wall distance, equal to 0.6 of the nozzle outer diameter.
\end{abstract}

\section{INTRODUCTION}

Heat and mass transfer between solid surfaces and impinging fluid jets has been a subject of numerous studies over the past four decades. The most important early results dealing with heat and/or mass transfer of the impinging jet (IJ) were summarized, e.g., in the outstanding monograph by Dyban and Mazur [1], and in the exceptional study by Martin [2]. Since then, several comprehensive reviews have appeared up to the present time, such as [3-7].

IJ generating from an annular nozzle, in other words an annular IJ, was frequently studied in the past. For example, Kokoshima et al. [8] studied numerically the annular IJs and predicted their bistable behavior (called in [8] as "closed" and "opened" flow patterns) including the associated hysteretic character of the flowfield.

Maki and Yabe [9] experimentally investigated annular IJs and identified four flow regimes. Three of these regimes were characterized as recirculating unsteady flows. The other experimental study of the same authors Maki and Yabe [10] was performed at the relatively large diameter ratio $D_{\mathrm{i}} / D_{\mathrm{o}}=$ 0.80 to 0.98 (where $D_{\mathrm{i}}$ and $D_{\mathrm{o}}$ are the inner and outer exit diameters, respectively). They clarified three flowfield patterns by means of hot-wire measurements, measurements of wall pressure distributions, and measurements of mass transfer rate distributions by the naphthalene sublimation technique. An existence of these flowfield patterns was unambiguously determined by the nozzle-to-wall distances - i.e., Maki and Yabe [9 and 10] did not found a hysteresis.

More recently, Tesař and Trávníček [11] investigated by numerical flowfield solutions an annular IJ with five flow regimes including bistability on the demarcation boundary between two of them. Surprisingly, no hysteresis was referred in $[9,10$, and 11] - the phenomenon is, apparently, not universal but depends on the specific geometry.

\begin{tabular}{|c|c|c|}
\hline \multicolumn{3}{|c|}{ NOMENCLATURE } \\
\hline$b_{\mathrm{SJ}}$ & {$[\mathrm{m}]$} & width of the SJ orifice, $b_{\mathrm{SJ}}=0.54 \mathrm{~mm}$, see Fig. 1 \\
\hline$D_{\mathrm{H}}$ & {$[\mathrm{m}]$} & hydraulic diameter of SJ orifice, $D_{\mathrm{H}}=2 b_{\mathrm{SJ}} w_{\mathrm{SJ}} /\left(b_{\mathrm{SJ}}+w_{\mathrm{SJ}}\right)$ \\
\hline$D_{\mathrm{i}}$ & {$[\mathrm{m}]$} & inner diameter of annular nozzle, $D_{\mathrm{i}}=74 \mathrm{~mm}$, see Fig. 1 \\
\hline$D_{\mathrm{o}}$ & {$[\mathrm{m}]$} & outer diameter of annular nozzle, $D_{\mathrm{o}}=84 \mathrm{~mm}$, see Fig. 1 \\
\hline$D_{\mathrm{n}}$ & {$\left[\mathrm{m}^{2} / \mathrm{s}\right]$} & mass diffusion coefficient of naphthalene vapor in air \\
\hline$h$ & {$\left[\mathrm{~W} /\left(\mathrm{m}^{2} \mathrm{~K}\right)\right]$} & local heat transfer coefficient \\
\hline$h_{m}$ & {$[\mathrm{~m} / \mathrm{s}]$} & local mass transfer coefficient \\
\hline$H$ & {$[\mathrm{~m}]$} & nozzle-to-wall spacing, see Fig. 6 \\
\hline IJ & & impinging jet \\
\hline$k$ & {$[\mathrm{~W} /(\mathrm{m} \mathrm{K})]$} & thermal conductivity of the working fluid (air) \\
\hline $\mathrm{Nu}$ & & local Nusselt number, $h D_{\mathrm{d}} / k$ \\
\hline $\operatorname{Pr}$ & & Prandtl number \\
\hline$r$ & {$[\mathrm{~m}]$} & radial coordinate (see Fig. 1) \\
\hline$R e_{\mathrm{D}}$ & & $\begin{array}{l}\text { Reynolds number of annular jet based on the outer } \\
\text { diameter at nozzle exit, } \bar{u} D_{\mathrm{o}} / v\end{array}$ \\
\hline $\operatorname{Re}_{\mathrm{SJ}}$ & & Reynolds number of control synthetic jet, $R e_{\mathrm{SJ}}=U_{\mathrm{SJ}} D_{\mathrm{H}} / \mathrm{N}$ \\
\hline$R e_{\mathrm{W}}$ & & $\begin{array}{l}\text { Reynolds number of annular slot jet based on the width } \\
\text { of the annular nozzle slot, } \bar{u} W / v\end{array}$ \\
\hline$S c$ & & Schmidt number for naphthalene vapor in air, $v / D_{n}$ \\
\hline$S h$ & & local Sherwood number, $h_{m} D_{\mathrm{d}} / D_{\mathrm{n}}$ \\
\hline SJ & & control synthetic jet \\
\hline$t$ & {$[\mathrm{~s}]$} & time \\
\hline$T_{\mathrm{w}}$ & {$[\mathrm{K}]$} & wall temperature \\
\hline $\bar{u}$ & {$[\mathrm{~m} / \mathrm{s}]$} & $\begin{array}{l}\text { area-averaged nozzle exit velocity of the main annular } \\
\text { jet }\end{array}$ \\
\hline$U_{\mathrm{SJ}}$ & {$[\mathrm{m} / \mathrm{s}]$} & time-mean orifice velocity of SJ, see Eq. (1) \\
\hline$W$ & {$[\mathrm{~m}]$} & slot width of the annular nozzle, $\left(D_{\mathrm{o}}-D_{\mathrm{i}}\right) / 2$ \\
\hline$w_{\mathrm{SJ}}$ & [m] & length of the SJ orifice, $w_{\mathrm{SJ}}=6.25 \mathrm{~mm}$, see Fig. 1 \\
\hline$x$ & {$[\mathrm{~m}]$} & axial coordinate, see Fig. 1 \\
\hline$v$ & {$\left[\mathrm{~m}^{2} / \mathrm{s}\right]$} & kinematic viscosity of the working fluid (air) \\
\hline$\rho$ & {$\left[\mathrm{kg} / \mathrm{m}^{3}\right]$} & density of the working fluid (air) \\
\hline
\end{tabular}


On the contrary, the experimental study by Trávníček and Tesař [12] confirmed the expected bistability and hysteresis effects: two different flow field patterns were identified under the same geometry and boundary conditions.

An actively controlled annular IJ was studied by Trávníček et al. [13]. The nozzle was designed to allow switching the jet by on/off fluidic control. The bistability and hysteretic effects were identified. It was demonstrated that steady annular IJs achieve very high heat/mass transfer rate on the impingement walls [11, 13]. It may be expected that an additional augmentation of transport processes is possible by means of an applied oscillation. Therefore, acoustically excited annular IJs were investigated by Trávníček and Tesař [14]. Two different regimes of the time-mean flow were adjusted by applying different excitation frequencies. An effective stabilization of the large recirculation bubble and a remarkable augmentation of average heat/mass transfer (by as much as $23 \%$ ) have been achieved at the Strouhal number 0.94. However, no hysteresis was identified by Trávníček and Tesař [14].

An active oscillatory flow control can be realized by means of a control synthetic jet (SJ). The SJ is generated (,synthesized") from a train of fluid puffs by pushing and pulling fluid through an actuator orifice [15-17]. The timemean mass flux of the oscillatory flow in the SJ actuator orifice is zero, hence the other common description of SJ is a zero-netmass-flux jet $[18,19]$. SJs can be utilized as a stand-alone SJ, investigated typically for cooling applications [20-23]. Another large field of SJ application is a heat transfer augmentation by means of an active flow control of primary steady flow fields e.g. as described in the recent papers dealing with laminar channel flows (Timchenko et al. [24], Trávníček et al. [25]) or round IJs [26].

Annular IJs, actively controlled by means of SJs, were studied by Trávníček and Tesař $[27,28]$. The active flow control system was designed with six radial round SJs, issuing from the central body of the nozzle. Either non-modulated [27] or modulated [28] actuation signal was used. The results have shown that heat/mass transfer rate distribution over the exposed wall can be controlled. The present paper focuses on another variant of that case - an annular IJ controlled by means of a system of twelve slot SJs. Results of some preliminary experiments with this annular jet, without the impingement effects, were presented recently in $[29,30]$.

\section{EXPERIMENTAL SETUP AND METHODS}

Figure 1 shows the schematic view of the annular nozzle tested in the present study. Experiments are conducted with air as the working fluid. The nozzle is oriented horizontally. The air is supplied by blowers (driven by electric motor with speed control) and passes through an orifice plate used for flow rate measurement. Upstream from the nozzle, the main airflow passes through a horizontal tube, which has inner diameter and length $46 \mathrm{~mm}$ and $0.8 \mathrm{~m}$, respectively. The nozzle is annular, its outside and inside exit diameters are $D_{\mathrm{o}}=84.0 \mathrm{~mm}$ and $D_{\mathrm{i}}=74.0 \mathrm{~mm}$, respectively (so that the annular slit width was $\left.W=\left(D_{\mathrm{o}}-D_{\mathrm{i}}\right) / 2=5.0 \mathrm{~mm}\right)$. The main nozzle contraction is 1.30 relative to the supply inlet area.
A similar annular nozzle was investigated recently by Trávníček et al. [13], when the main annular jet was actively controlled by a steady radial jet, which was generated by pressurised air inflow. In contrast to that case, the present study uses a system of twelve radial SJs. For this reason, the nozzle is equipped with an electrodynamically driven SJ actuator, which is built into the central nozzle body. The actuator consists of a sealed cavity with an actuating diaphragm (originated from the loudspeaker Monacor SP-6/4, with the nominal electric input impedance $4 \Omega$, nominal input driving electric power $3 \mathrm{~W} \mathrm{rms}$, and the diaphragm diameter $D_{\mathrm{D}}=46.0 \mathrm{~mm}$ ). In the present study, the input electrical power of the sinusoidal current fed into the actuator was kept constant at $1.0 \mathrm{~W}$ applied at different frequencies. The actuator cavity is opened via twelve radial slot orifices, located equidistantly around the center body perimeter (see Fig. 1). The width and length of the orifices are $b_{\mathrm{SJ}}=$ $0.54 \mathrm{~mm}$ and $w_{\mathrm{SJ}}=6.25 \mathrm{~mm}$. Each of the orifices generates a radial SJ. More details of the performed measurements and investigations are available in the research report by Broučková et al. [29].

(a)

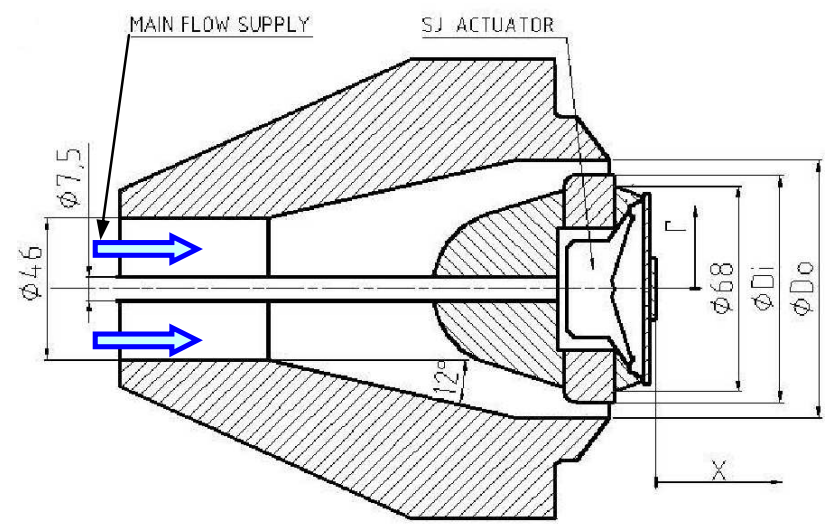

(b)

(c)
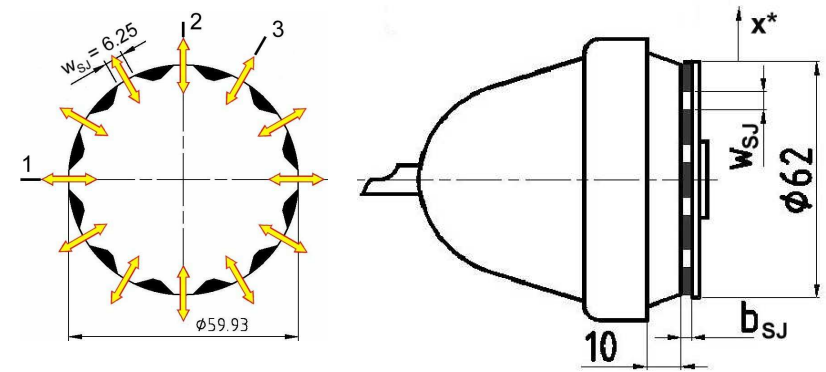

Figure 1 Annular nozzle with SJ actuator; (a) assembled nozzle, (b) front view of the twelve radial SJs (numbers 1-3 show the traversing lines of the Pitot Probes in Figs. 2 and 3), (c) detail of the center body of the nozzle. Dimensions: $D_{\mathrm{o}}=84.0 \mathrm{~mm}, D_{\mathrm{i}}=74.0 \mathrm{~mm}, b_{\mathrm{SJ}}=0.54 \mathrm{~mm}, w_{\mathrm{SJ}}=6.25 \mathrm{~mm}$ 
The smoke-wire technique is used for flow visualization, similarly as in [13 and 14]. The time-mean flowfield pattern (phase-locked streaklines) are observed and photographed by a digital camera.

The local mass transfer was measured using the naphthalene sublimation method. The local mass-transfer coefficient is evaluated from the sublimation depth following the descriptions in $[1,13-14,25-27,31]$ as $h_{\mathrm{m}}=\rho_{\mathrm{n}} R_{\mathrm{n}} T_{\mathrm{w}} \Delta y /\left(p_{\text {sat }} \Delta t\right)$, where $\rho_{\mathrm{n}}$ is the density of solid naphthalene $\left(\rho_{n}=1175 \mathrm{~kg} / \mathrm{m}^{3}\right.$ at $\left.20^{\circ} \mathrm{C}\right)$, $R_{\mathrm{n}}$ is the gas constant for naphthalene $\left(R_{n}=64,87 \mathrm{~J} /(\mathrm{kg} \mathrm{K})\right), T_{\mathrm{w}}$ is the surface temperature, $\Delta y$ is the net local sublimation depth, $p_{\text {sat }}$ is the saturated vapor pressure of naphthalene at $T_{\mathrm{w}}$ [31], and $\Delta t$ is the run duration. The maximum sublimation depth $\Delta y$ was $0.1 \mathrm{~mm}$ at the typical run duration of $\Delta t$ from $90 \mathrm{~min}$ to 105 min.

The non-dimensionalised quantity characterizing the masstransfer coefficient is the Sherwood number, $\left(S h=h_{\mathrm{m}} D_{\mathrm{o}} / D_{\mathrm{n}}\right)$, where $D_{\mathrm{n}}$ is the mass diffusion coefficient of naphthalene vapor in air, calculated for the measured temperature and pressure [31]. Similarly as the Sherwood number, the Nusselt number is defined as $N u=h D_{0} / k$, where $h$ is the local heat transfer coefficient and $k$ is the thermal conductivity. The experimentally evaluated mass transfer data can be transformed to predict the heat transfer at the isothermal boundary condition using the heat/mass transfer analogy $[1,31]: S h / S c^{n}=N u / P r^{n}$, where $\operatorname{Pr}$ and Sc are the Prandtl and Schmidt numbers, respectively. The $S c$ is calculated for $T_{\mathrm{w}}$ according to the empirical equation [31] (a typical value is 2.286 at $20^{\circ} \mathrm{C}$ ), and the exponent $n$ is taken to be 0.40 in this study, similarly as in [13].

Uncertainty analysis was performed according to Kline and McClintock's method for single sample experiment [32]. The uncertainty of the mass transfer coefficient and the Sherwood number are within $6 \%$ and $9 \%$ (based on a $95 \%$ confidence level, i.e. \pm 2 standard deviation). A more detailed description of the naphthalene sublimation method and evaluation of its uncertainties were described in [13].

The time-mean pressure on the wall was measured by a digital manometer with $0.1 \mathrm{~Pa}$ resolution (Greisinger GMH 3156 , with pressure sensor GMSD 2.5MR). The diameter of the pressure tap hole drilled through the wall was $0.9 \mathrm{~mm}$.

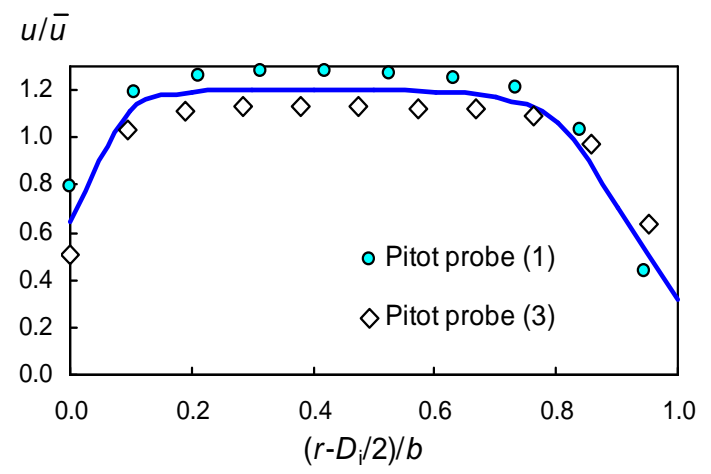

Figure 2 Velocity profile measured at the annular nozzle outlet $(x=0.3 \mathrm{~mm}) ; \bar{u}=3.9 \mathrm{~m} / \mathrm{s}, R e_{\mathrm{D}}=21300,\left(R e_{\mathrm{W}}=1270\right)$; numbers 2 and 3 indicate different traversing lines (Fig. 1(b))
The time-mean flow velocity was measured by the Pitot tube (blunt-nosed impact tube with the outer diameter of $0.8 \mathrm{~mm}$ ), connected to the above mentioned electronic manometer. Considering the static pressure to be equal to barometric, the measured time-mean total pressure $p$ was converted into the time mean velocity: $u=(2 p / \rho)^{0.5}$.

Instantaneous velocity of $\mathrm{SJ}$ was measured recently by Broučková et al. [29], by means of the hot-wire anemometer in the constant temperature anemometry (CTA) mode (MiniCTA 54T30 Dantec, with the single wire probe 55P16).

Two thermocouples of type $\mathrm{K}$ were used to measure air temperature. They were located in the main supply tubing (or in the nozzle exit before each test run) and in the ambient. All experiments were made after thorough temperature equalisation.

\section{RESULTS AND DISCUSSIONS}

Figure 2 shows the velocity profiles, which were measured in the annular nozzle outlet without an applied control by SJs. Two measurements were made, repeated at two positions of the nozzle perimeter (see Fig. 1(b)). Fig. 2 shows also the average profile. This is quite flat at the short streamwise distance where there is the jet core. The slopes at its boundaries are seen to be larger at the outer part of the profile than at the inner part.

\section{Frequency characteristics of the SJ actuator, and the flow control parameters}

Figure 3 shows the frequency characteristics of the SJ actuator. The velocity measurements were made downstream from of the actuator orifices, without the main annular jet flow, moderately far downstream from the exits - at the distance $x^{*}=7.2 \mathrm{~mm}$ where the longitudinal velocity component of SJ can be expected to be always positive - cf. [29]. Figure 3 shows three data sets. Two measurements were made by the Pitot probe at two different points of the nozzle perimeter, namely at positions 1 and 2 - see Fig. 1(b). For comparison purposes, CTA data [29] are also presented (CTA probe was at the position 2). All three results are in good agreement, i.e. the distribution of SJs around the perimeter is sufficiently uniform.

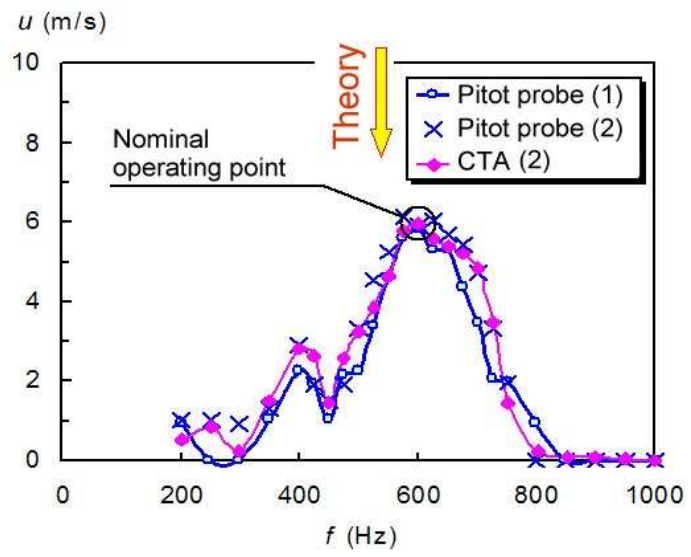

Figure 3 Frequency characteristic of the used synthetic jet actuator; numbers 1 and 2 indicate the traversing lines - see Fig. 1(b) 
An agreement between the Pitot probe and the CTA measurements indicates that the oscillation component of velocity at the measurement positions was not dominant. Figure 3 shows that the maximum time-mean velocity $(u=6.0 \mathrm{~m} / \mathrm{s})$ was achieved approximately at $f=600 \mathrm{~Hz}$. This maximum corresponds to the first resonance of the actuator. Note that this value agrees rather well with the theoretical natural frequency $541 \mathrm{~Hz}$, which is indicated by the arrow named "Theory" in Fig. 3. More details of the derivation and evaluation of the natural frequency of SJ actuator are written in paper by Trávníček et al. [25].

Assuming the slug flow model of SJ, the time-mean orifice velocity is defined (as usual, [15]):

$$
U_{\mathrm{SJ}}=f \int_{0}^{T_{\mathrm{E}}} u_{0}(t) d t,
$$

where $T_{\mathrm{E}}$ is the extrusion time and $u_{0}(t)$ is the velocity at the orifice exit. The Reynolds number and the stroke length are defined as $R e_{\mathrm{SJ}}=U_{\mathrm{SJ}} D_{\mathrm{H}} N$ and $L_{\mathrm{SJ}}=U_{\mathrm{SJ}} T$, respectively, where $v$ is the kinematic viscosity, $T$ is the time period $T=1 / f$, and $D_{\mathrm{H}}$ is the hydraulic diameter of the SJ orifice, $D_{\mathrm{H}}=2 b_{\mathrm{SJ}} w_{\mathrm{SJ}} /\left(b_{\mathrm{SJ}}+w_{\mathrm{SJ}}\right)$.

Based on the result shown in Fig. 3, the frequency $f=600 \mathrm{~Hz}$ was chosen as the nominal operating point (the input electrical power was kept constant $1.0 \mathrm{~W}$, as written above). The parameters of $\mathrm{SJ}$ at this nominal operating point were evaluated by means of CTA [29] as $U_{\mathrm{SJ}}=5.8 \mathrm{~m} / \mathrm{s}, R e_{\mathrm{SJ}}=372$ and $L_{\mathrm{SJ}} / D_{\mathrm{H}}=9.7$.
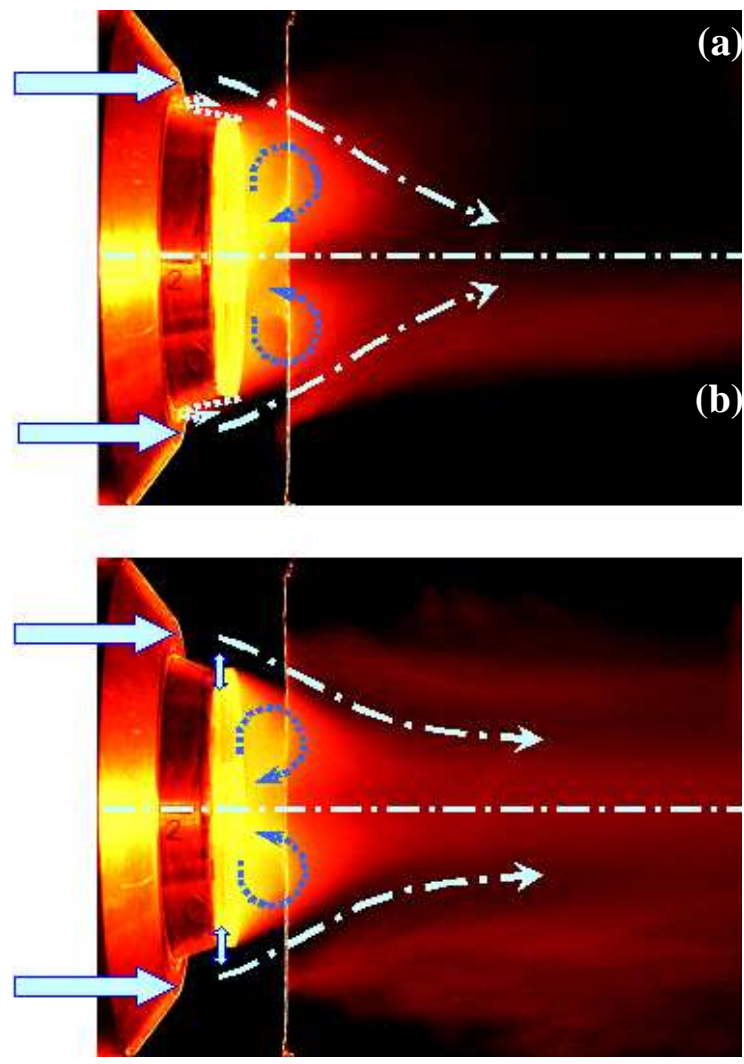

Figure 4 Flow visualization; (a) annular jet without control by SJ, (b) annular jet with control by SJ
The strength of the control SJs can be quantified by relating to the main annular jet in terms of the ratios of velocities, flow rates, and momentum rates as

$$
\begin{aligned}
& c_{\mathrm{U}}=\frac{U_{\mathrm{SJ}}}{U_{\mathrm{AJ}}}, \\
& c_{\mathrm{Q}}=\frac{n A_{\mathrm{SJ}} U_{\mathrm{SJ}}}{A_{\mathrm{AJ}} U_{\mathrm{AJ}}},
\end{aligned}
$$

and

$$
c_{\mathrm{m}}=n\left(\frac{A_{\mathrm{SJ}}}{A_{\mathrm{AJ}}}\right)\left(f \int_{0}^{T_{\mathrm{E}}} u_{0}^{2}(t) d t\right)\left(\frac{1}{U_{\mathrm{AJ}}^{2}}\right)=n\left(\frac{\pi}{2}\right)^{2}\left(\frac{A_{\mathrm{SJ}}}{A_{\mathrm{AJ}}}\right)\left(\frac{U_{\mathrm{SJ}}}{U_{\mathrm{AJ}}}\right)^{2},
$$

respectively, where $n$ is the number of control SJs ( $n=12$ for in the present geometry), and $A_{\mathrm{SJ}}$ and $A_{\mathrm{AJ}}$ are the cross sectional area of the SJ orifice $\left(A_{\mathrm{SJ}}=b_{\mathrm{SJ}} w_{\mathrm{SJ}}\right)$ and the main annular jet $\left(A_{\mathrm{SJ}}=\pi\left(D_{\mathrm{o}}^{2}-D_{\mathrm{i}}^{2}\right) / 4\right)$, respectively.

In the present study, these ratios were evaluated to be $c_{\mathrm{U}}=1.49, \quad c_{\mathrm{Q}}=4.9 \%$, and $c_{\mathrm{m}}=17.8 \%$. For example, Tamburello and Amitay [33] successfully vectored a round air jet at even much smaller $c_{\mathrm{m}}=0.0062$ (note that they used slightly different constant in the definition Eq. (6), $\left.C_{\mu}=8 c_{\mathrm{m}} / \pi^{2}=0,81 c_{\mathrm{m}}\right)$. More recently, Trávníček et al. [26] measured heat/mass transfer of round IJ, which was excitated by SJs into the helical mode at $c_{\mathrm{U}}=0.053-0.17, c_{\mathrm{Q}}=0.018$ 0.057 , and $c_{\mathrm{m}}=0.0024-0.024$.

\section{Flow field idea and annular IJ}

Figure 4 shows two typical flow visualization results of the studied annular jet, where the cases (a) and (b) correspond to the control SJs being turned off or on, respectively. The visualization demonstrates that the actuation causes a distinguishable widening of the main annular jet - see Fig. 4(b).

Figure 5 shows the velocity profiles measured at $x=$ $40 \mathrm{~mm}$, i.e. $x / D_{0}=0.476$. Similarly as the visualization result in Fig. 4, the velocity profiles in Fig. 5 demonstrate that SJ control causes a distinguishable widening of the main annular jet. This annular jet spreading is intended to be used in the case of IJ for spreading of the area with enhanced heat transfer. However, a penalty of this effect is the rather large reduction of the maximum velocity at the jet axis (by $18 \%$ in Fig. 5).

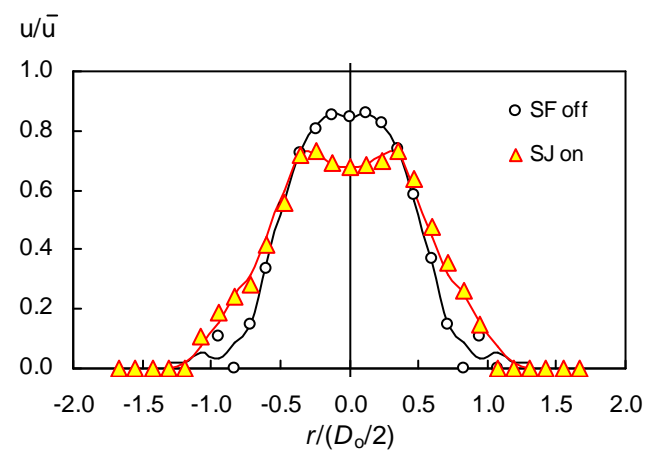

Figure 5 Velocity profiles measured at $x=40 \mathrm{~mm}\left(x / D_{0}=\right.$ 0.476 ) - comparison of the main jet with/without SJ control 
(a)

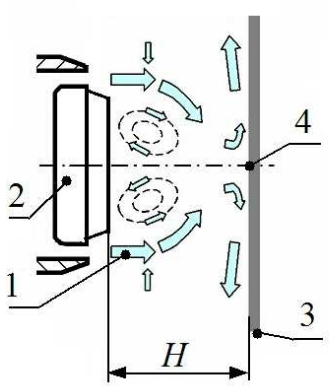

(b)

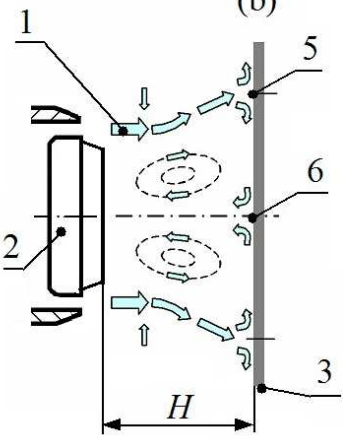

Figure 6 Flowfield patterns of the annular impinging jets: (a) A-pattern, small recirculation region (bubble), (b) B-pattern, large recirculation region. 1: annular jet, 2: nozzle centerbody, 3: impingement wall, 4: central stagnation point, 5: stagnation circle, 6: reverse stagnation point, $H$ : nozzle-to-wall spacing

According to the previous experience, two different flow field patterns of an annular IJ can be expected at the given conditions $-[13,14]$. The patterns A and B differ in the size of the recirculation region of the separated flow, as is schematically presented in Fig. 6:

- Pattern A, see Figs. 6(a): with the small recirculation region (bubble) of separated flow, located immediately downstream from the nozzle center body. On the impingement wall there is only the central stagnation point positioned on the nozzle axis and no other stagnation objects.

- $\quad$ Pattern B, see Figs. 6(b): the large recirculation region of separated flow, which reaches up to the impingement wall where there is a stagnation circle. The central stagnation point is now at the location where the fluid in the separated-flow bubble leaves the surface - the so-called reverse stagnation point $[9,10]$. The entire space between the nozzle exit inner circle and the stagnation circle is filled with the standing vortex ring of recirculating fluid.

Figure 7 presents two typical results of the stagnation pressure measured at the central point on the wall - intersection of the nozzle axis with the wall, $r=0: p_{\mathrm{w} 0}$ is the wall pressure difference relative to the barometric pressure at the central point and $q_{\mathrm{o}}$ is the dynamic pressure calculated from the timemean velocity measured (by the Pitot probe) in the nozzle exit. The two data sets correspond to the flowfield with and without flow control by SJs. The flowfield patterns A and B correspond to the higher and lower stagnation pressures, respectively, as is labeled in Fig. 7. However, Fig. 7 indicates that a flowfield behavior is non-monotonic and rather complicate in the range of $H / D_{\mathrm{o}}=0.3-0.9$. Based on Fig. 7, three nozzle-to-wall spacings were chosen for the following experiments, as is in Fig. 7 indicated by the vertical dashed lines.

Figure 8 shows three wall pressure distributions measured without the SJ flow control. While the flowfield pattern A with the central stagnation point occurs at larger nozzle-to-wall $p_{\mathrm{wo}_{0}} / \mathrm{q}_{0}$

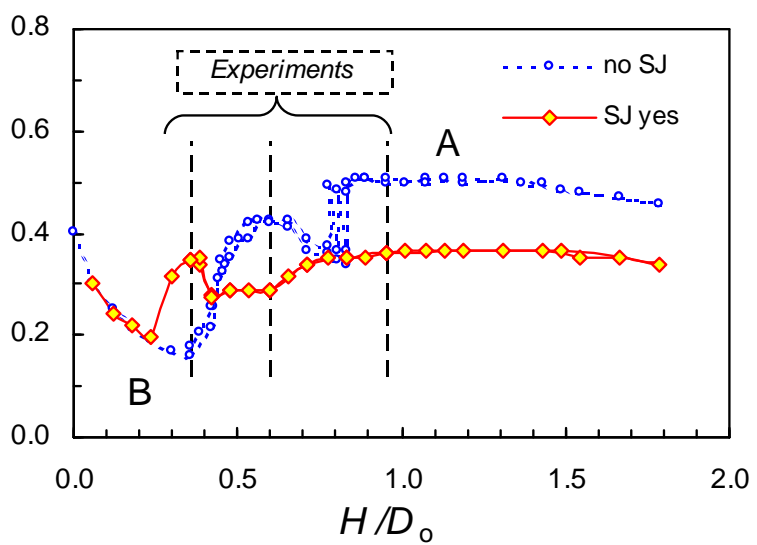

Figure 7 Wall pressure measured at the central point on the wall $(r=0)$ - comparison of the annular impinging jet with and without flow control by SJ

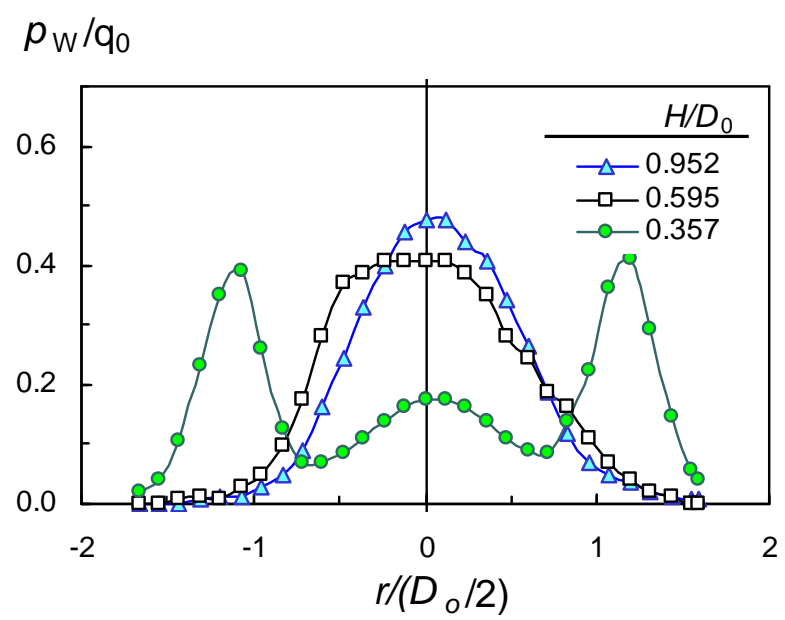

Figure 8 Wall pressure distributions measured without control SJs

spacings of $H / D_{\mathrm{o}}=0.952$ and 0.595 , the pattern $\mathrm{B}$ with the stagnation circle and the central reverse stagnation point occurs at smaller $H / D_{\mathrm{o}}=0.357$.

\section{Local mass transfer on the impingement wall}

Figure 9 presents the typical results of the local mass transfer measurement at the nozzle-to-wall spacing of $H / D_{0}=0.952$, 0.595 , and 0.357 (the same $H / D_{\mathrm{o}}$ as for the above discussed wall pressure experiments). As discussed above, the flowfield depends on the $H / D_{\mathrm{o}}$, and is influenced by SJs:

- According to the expectation, larger $H / D_{0}=0.952$ is linked with the flowfield pattern A. The heat/mass transfer distribution is approximately bell-shaped with the maximum in the central stagnation point, as is shown in Fig. 9(a). The SJ actuation reduces the maximum at the jet axis, which agrees with the velocity reduction there - cf. Fig. 5. Unfortunately, the desirable spreading of the area 
with enhanced heat transfer was not found in this experiment for $H / D_{\mathrm{o}}=0.952$.

- Basically different is the result at the moderate nozzle-towall spacing of $H / D_{0}=0.595$, as shown in Fig. 9(b). The flowfield pattern $B$ exhibits the stagnation circle at which there is the local maximum of the heat/mass transfer intensity. The SJ actuation enhances this maximum by approximately $20 \%$, as is shown in Fig. 9(b). However, no significant spreading of the area with enhanced heat transfer has been so far achieved.

- The heat/mass transfer distribution for small nozzle-to-wall spacing of $H / D_{0}=0.357$ demonstrates well the flowfield pattern B, with the stagnation circle. Surprisingly, the flow control for this nozzle-to-wall spacing causes a contraction of the area with enhanced heat transfer, thus the stagnation circle is reduced by the flow control. Although the central area exhibits unambiguously an enhancement effect, the unwanted contraction of this area degrades this positive effect. As a result, the flow control at $H / D_{\mathrm{o}}=0.357$ in not contributing to a desirable heat/mass transfer augmentation.
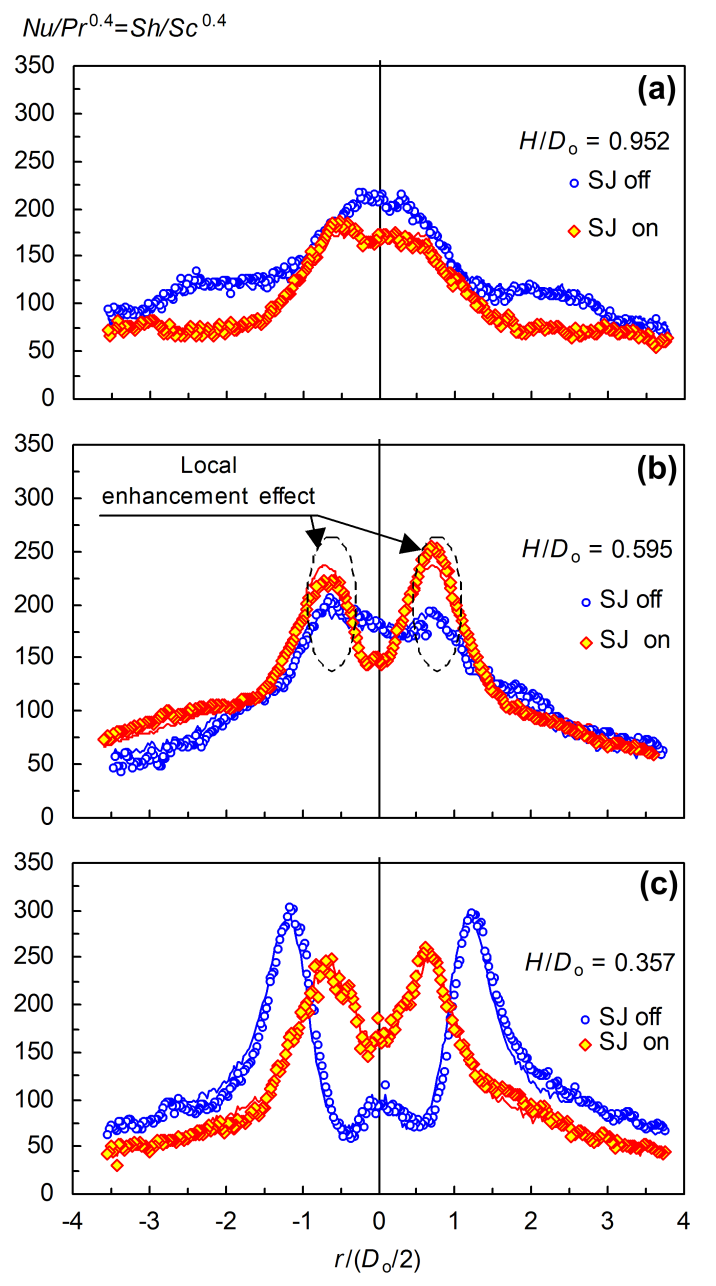

Figure 9 Local heat/mass transfer distribution of the present annular impinging jet with and without SJ control

\section{CONCLUSIONS}

An annular nozzle was equipped with an electrodynamically driven actuator generating twelve radial (zero-net-mass-flux) slot synthetic jets from the center body of the nozzle. The possibility of an active flow control by these SJs has been demonstrated. A desirable heat/mass transfer augmentation by means of the active flow control was found only for the moderate nozzle-to-wall spacing. The SJ actuation then can enhance the local heat/mass transfer maximum by approximately $20 \%$. However, no significant spreading of the area with enhanced heat transfer has been achieved for this particular geometry in the experiments performed so far.

\section{Acknowledgment}

Authors acknowledge gratefully the support of the GA AS CR (project No. IAA 200760801) and Grant Agency of CR (project No. P101/11/J019).

\section{REFERENCES}

[1] Dyban E.P., Mazur A.I., Convection Heat Transfer in Impinging Jets (Konvektivnyj teploobmen pri strujnom obtekanii tel), $1^{\text {st }}$ ed., Naukova dumka, Kiev, 1982 (in Russian).

[2] Martin H., Heat and mass transfer between impinging gas jets and solid surfaces, Advances in Heat Transfer, Vol. 13, 1977, pp. 1-60.

[3] Downs S.J., and James E.H., Jet impingement heat transfer - a literature survey, Proceedings of the National Heat Transfer Conference, ASME, Pennsylvania, PA, 1987, 87-HT-35.

[4] Jambunathan K., Lai E., Moss M.A., and Button B.L., A review of heat transfer data for single circular jet impingement, International Journal of Heat and Fluid Flow, Vol. 13 (2), 1992, pp. $106-115$.

[5] Viskanta R., Heat transfer to impinging isothermal gas and flame jets, Experimental Thermal and Fluid Science, Vol. 6, 1993, pp. $111-134$.

[6] Webb B.W., and Ma C-F., Single-phase liquid jet impingement heat transfer, Advances in Heat Transfer, Vol. 26, 1995, pp. 105107.

[7] Garimella S.V., Heat transfer and flow fields in confined jet impingement, Annual Review of Heat Transfer, Vol. XI, 2000, pp. 413-494.

[8] Kokoshima Y., Shimizu A., and Murao T, Numerical analysis of annular turbulent jet impinging on a flat plate, Proceedings of the 3rd Triennial International Symposium on Fluid Control, Measurement, and Visualization, FLUCOME '91, San Francisco, ASME 1991, pp. 205-210.

[9] Maki H., and Yabe A., Unsteady characteristics of the annular impinging jet flow field and reverse stagnation point heat transfer, Proceedings of the National Heat Transfer Conference Heat Transfer in Convective Flows, Philadelphia, PA, 1989, HTDVol.107, pp. 163-168.

[10] Maki H., and Yabe A., Heat transfer by the annular impinging jet. Experimental Heat Transfer, Vol. 2, 1989, pp. 1-12.

[11] Tesař V., and Trávníček Z., Increasing heat and/or mass transfer rates in impinging jets, Journal of Visualization, Vol. 8 (2), 2005, pp. 91-98.

[12] Trávníček Z., and Tesař V., Hysteretic behavior of annular impinging jets, $C D$ Proceedings of 5th European Thermal-Sciences Conference, Eindhoven, May 18-22, 2008, JET 6.

[13] Trávníček Z., Peszyński K., Hošek J., and Wawrzyniak S., Aerodynamic and mass transfer characteristics of an annular bistable 
impinging jet with a fluidic flip-flop control. International Journal of Heat and Mass Transfer, Vol. 46, 2003, pp. 1265-1278, 2003.

[14] Trávníček Z., and Tesař V., An annular impinging jet with recirculation zone expanded by acoustic excitation, International Journal of Heat and Mass Transfer, Vol. 47, 2004, pp. 2329-2341.

[15] Smith B.L., and Glezer A., The formation and evolution of synthetic jets, Physics of Fluids, Vol. 10, 1998, pp. 2281- 2297.

[16] Mallinson S.G., Reizes J.A., and Hong G., An experimental and numerical study of synthetic jet flow, The Aeronautical Journal, Vol. 105 (1043), 2001, pp. 41-49.

[17] Tesař V., and Zhong S., Efficiency of Synthetic Jet Generation, Transactions of the Aeronautical and Astronautical Society of the Republic of China, Vol. 35, 2003, pp. 45-53.

[18] Pack L.G., and Seifert A., Periodic Excitation for Jet Vectoring and Enhanced Spreading, Journal of Aircraft, Vol. 38 (3), 2001, pp. 486-495.

[19] Cater J.E., and Soria J., The evolution of round zero-net-massflux jets, Journal of Fluid Mechanics, Vol. 472, 2002, pp. 167-200.

[20] Kercher D.S., Lee J.-B., Brand O., Allen M.G., and Glezer A., Microjet cooling devices for thermal management of electronics, IEEE Transactions on Components and Packaging Technologies, Vol. 26 (2), 2003, pp. 359-366.

[21] Trávníček Z., and Tesař V., Annular synthetic jet used for impinging flow mass-transfer, International Journal of Heat and Mass Transfer, Vol. 46 (17), 2003, pp. 3291-3297.

[22] Arik M., An investigation into feasibility of impingement heat transfer and acoustic abatement of meso scale synthetic jets, Applied Thermal Engineering, Vol. 27, 2007, pp. 1483-1494.

[23] Persoons T., McGuinn A., and Murray D.B., A general correlation for the stagnation point Nusselt number of an axisymmetric impinging synthetic jet, International Journal of Heat and Mass Transfer, Vol. 54, 2011, pp. 3900-3908.

[24] Timchenko V., Reizes J.A., and Leonardi E., An evaluation of synthetic jets for heat transfer enhancement in air cooled microchannels, International Journal of Numerical Methods for Heat \& Fluid Flow, Vol. 17, (3), 2007, pp. 263-283.

[25] Trávníček Z., Dančová P., Kordík J., Vít T., and Pavelka M., Heat and mass transfer caused by a laminar channel flow equipped with a synthetic jet array. ASME Journal of Thermal Science and Engineering Applications, Vol. 2 (4), 2010, 041006-1 - 041006-8.

[26] Trávníček Z., Němcová L., Kordík J., Tesař V., and Kopecký V., Axisymmetric impinging jet excited by a synthetic jet system. International Journal of Heat and Mass Transfer, Vol. 55 (4), 2012, pp. $1279-1290$.

[27] Trávníček Z., and Tesař V., Synthetic jets used to control spreading of an annular impinging jet. CD Proceedings of the International Symposium on Flow Visualization, ISFV13/ FLUVISU12, Nice, France, July 1-4, 2008, No. 107.

[28] Trávníček Z., and Tesař V., An annular impinging jet alternated by pulse-modulated synthetic jets. $C D$ Proceedings of the 8th ASME-JSME Thermal Engineering Joint Conference (AJTEC2011), Honolulu, Hawaii, USA, March 13- 17, 2011, AJTEC2011-44128.

[29] Broučková Z., Kordík J., and Trávníček Z., Aktivní řízení anulárního proudu radiálním syntetizovaným proudem (Active control of an annular jet by a radial synthetic jet. Research Report $Z$ 1438/09, Institute of Thermomechanics AS CR, 2009 (in Czech).

[30] Tesař V., Broučková Z., Kordík J., Trávníček Z., and Peszyński K., Valves with flow control by synthetic jets. Proceedings of the International Conference Experimental Fluid Mechanics, TU Liberec, Jičín, Czech Republic, Nov. 22-25, 2011, pp. 988-1003.

[31] Goldstein R.J., and Cho H.H., A review of mass transfer measurements using naphthalene sublimation, Experimental Thermal and Fluid Science, Vol. 10, 1999, pp. 416-434.
[32] Kline S.J., and McClintock F.A., Describing uncertainties in single-sample experiments, Mechanical Engineering, Vol. 75, 1953, pp. 3-8.

[33] Tamburello D.A., and Amitay M., Three-dimensional interactions of a free jet with a perpendicular synthetic jet, Journal of Turbulence, Vol. 8 (38), 2007, pp. 1-21. 